\title{
FUNDING COMMON PROPERTY EXPENDITURE IN MULTI-OWNED HOUSING SCHEMES
}

\begin{abstract}
This paper appraises the relative merits of the three main options to funding common property capital expenditure in multi-owned housing $(\mathrm{MOH})$ schemes. The three approaches are: 1) raising funds from unit owners at the time a common property capital expenditure is required (widely referred to as a 'special levy'); 2) debt funding; and 3) accumulation of a fund from unit owners prior to common property capital expenditure. A set of criteria is advanced for appraising the relative merits of these funding options. At a generalised level of abstraction, it appears that the accumulation of a fund prior to capital expenditure represents the preferred option.
\end{abstract}

Key words: Condominiums, strata title, reserve fund, sinking fund, special levy. 


\section{FUNDING COMMON PROPERTY EXPENDITURE IN MULTI-OWNED HOUSING SCHEMES}

\subsection{Introduction}

In this paper, a multi-owned housing $(\mathrm{MOH})$ scheme is defined as a group of accommodation units where each unit owner owns the space within their unit, and all unit owners collectively own areas of common property in their complex. When referring to such complexes, the term 'condominium' is widely-used in the USA and 'strata title' is widely-used in Australia.

A fundamental challenge in $\mathrm{MOH}$ schemes concerns the need for owners to act collectively in the interests of the complex that they own in common (Christudason, 2004; Encon, 2005; Randolph, 2006; Walters, 2002). This problem is particularly evident with respect to the long-term maintenance of a MOH complex's common property. Common property refers to a MOH scheme's real property that is either collectively owned by all the unit holders or vested in the party that represents the owners collective. Typical examples of common property include exterior walls, balconies, roof and elevator in a high rise complex.

This study focuses on the relative merits of different approaches to the raising of funds in a $\mathrm{MOH}$ scheme to finance common property capital expenditure. Capital expenditure refers to nonrecurrent expenditure and includes periodic renewal and replacement of major items. Examples of capital expenditure include major roof repairs, exterior wall painting, or a major overhaul of an elevator. ${ }^{\mathrm{i}}$

The specific objectives of this paper are to advance a set of criteria for appraising the merits of alternative options to financing common property capital expenditure in $\mathrm{MOH}$ complexes and to then draw on this conceptual framework to determine which mode of common property capital expenditure funding is preferable. The application of a priori reasoning constitutes the primary methodology applied in the paper.

A challenge in an examination such as this surrounds terminology usage, as terms vary across legal jurisdictions. To facilitate exposition of issues, it is therefore helpful to focus on a particular country. Due to the domicile of the authors, the paper's discussion has been couched broadly in the Australian context. This has resulted in the deployment of Australian terminology such as 'owners executive committee', which is the elected executive of the owners in a strata titled complex, ${ }^{\mathrm{ii}}$ and a 'lot' (an individual 'unit' or 'apartment' in a MOH complex). This problem of inconsistent terminology is not only a trans-national challenge. Everton-Moore et al (2006) note the degree of variability in the way condominium terms are used across the Australian states and territories. The USA also has state specific MOH legislation.

The remainder of the paper is structured as follows. The next section provides literary context for the study. The subsequent section advances a set of criteria that will provide an underlying framework for the examination of the relative merits of distinct common property capital expenditure funding options. The three funding options are then described, followed by a critical examination of the extent to which the funding options satisfy the identified criteria. The paper's final section provides a conclusion and discussion of issues arising.

\subsection{Literature}

Broad context for this study is provided by Blandy et al's (2010) book that explores the interrelationships occurring between power, law and practice in the governance of multi-owned 
residential developments across a range of countries. A noteworthy aspect of this book concerns its international orientation. This highlights the relevancy of this study to a very significant stock of housing internationally. The ubiquitous uptake of the $\mathrm{MOH}$ model appears as inconsistent with the paucity of academic examination of the model's workings, however. As Easthope and Randolph (2009; 244) comment:

... given the increasing role higher density housing is playing in urban development, it is surprising that issues surrounding the governance of strata title, the predominant ownership and management form by which higher density housing is developed and owned in Australia, have received so little academic attention.

Facets of the $\mathrm{MOH}$ model that have commanded some academic attention include dealing with diverse stakeholders, owner and resident representation (Easthope and Randolph (2009), and problems of scheme termination (Sherry, 2006). Ngai-ming and Forrest (2002) highlight the potential for tension to arise between owners with differing levels of wealth and Blandy et al (2006) note conflict of interest issues resulting when a developer attempts to extend a long-term service contract to a building managing agent. A specific $\mathrm{MOH}$ scenario was investigated by Guilding and Whiteoak (2008), who examined governance issues arising between accommodation owners and golf club managers in residential golf complexes.

There is also a literature that has examined governance issues arising in $\mathrm{MOH}$ complexes used extensively for tourism accommodation. In this context, Guilding et al (2006) provide an agency based analysis of inter-stakeholder relationships. They observed goal congruency to be higher between building managers and investor owners, relative to between building managers and resident owners. The merits of different modes of building manager service delivery were examined by Cassidy and Guilding (2011), while Warnken and Guilding (2009) comment on the problem of marketing and also pricing short-term lettings when apartments in the same building have different styles and levels of refurbishment.

With respect to $\mathrm{MOH}$ common property maintenance, Gruis et al (2009) comment on how the European Union states' legislation's failure to keep up with evolving home ownership dynamics has resulted in inadequate systems and structures to ensure continuous $\mathrm{MOH}$ common property maintenance. Muhamad Ariff and Davies (2011) collected data from multi-owner housing properties in Malaysia. While their study was primarily focused on examining for relationships between occupancy factors and owner-occupant characteristics affecting stakeholders' relationships, Muhamad Ariff and Davies (2011) also reported that only 15\% of the owners' associations that they investigated charged owner levies for the purpose of raising a common property capital expenditure sinking fund.

Lujanen (2010) conducted a cross-country investigation of differences in the way legislation requires common properties to be maintained. He focused on ten European countries and also Canada, China, Russia and the USA. While Lujanen (2010) noted significant jurisdictional differences, of particular pertinence to this study is his claim: "In principle, the use of reserve funds together with loan finance should always be used as a main part of the total financial package" (p.182). Other than noting that the longevity of repairs signifies the costs should be divided up over an extended period, he failed, however, to provide any substantive rationale in support of this claim. This points to the key contribution of the analysis reported herein, as no prior study has provided a structured examination of the relative merits of alternative common property expenditure funding methods. 
Easthope, Randolph and Judd (2012) conducted a large study that examined a broad range of issues relating to $\mathrm{MOH}$ properties. The study included an appraisal of owner satisfaction with budgeting practices and they cite an interviewee who expressed concern that in some properties inequity between owners arises as a result of plans for asset replacement failing to project beyond a ten year period. Referring to the under-funding of such asset replacement, they comment "previous owners who have now sold their properties have not contributed, so the new and current owners have to pay more than would reasonably be expected if there hadn't been shortfalls in the past (2012; 7778). The importance of legislating for this aspect of $\mathrm{MOH}$ management is apparent from the New South Wales state government (2012) law reform discussion paper that specifically encourages the submission of suggested policies in connection with whether the raising of long term funds to finance planned common property capital expenditures should be mandatory.

\subsection{Criteria for appraising merit of MOH common property capital expenditure funding options}

This section advances the set of criteria that will provide the framework for appraising the merit of alternative common property capital expenditure options. We see a broad, holistic, criterion and a set of more narrowly-defined subsidiary criteria. The broad criterion is:

The funding approach should facilitate common property infrastructure being of a quality and functionality that is consistent with the level of physical, social, aesthetic and economic amenity provided by the property at the beginning of the MOH complex’s life.

This will simply be referred to as "the common property sustainability" criterion. To demonstrate satisfaction of this holistic criterion, we would need to collect data showing that application of a particular common property capital expenditure funding approach results in adequate on-going common property repair, replacement, refurbishment and renovation in $\mathrm{MOH}$ complexes. It is unrealistic, however, to expect that any particular funding approach would always result in satisfactory common property standing. This is because factors unrelated to the funding approach adopted can materially affect the physical standing of common property (eg, a natural disaster or personal and political issues arising between owners can adversely affect the common property expenditure decision making process). A shortcoming of any attempt to gauge the achievement of this holistic criterion is that it is practically based and requires the exercise of some subjectivity, ie, it needs an appraisal to be made with respect to the manner and extent to which common property is maintained.

At the subsidiary criteria level, we see five desirable features in a common property capital expenditure funding approach. These are:

1. cost efficiency, ie, minimising total cost incurred by owners over the life of a $\mathrm{MOH}$ complex,

2. horizontal equity, ie equity in the allocation of cost across individual lot owners at a particular time juncture,

3. temporal equity, ie, equity in the allocation of costs to different lot owners over the life of a MOH complex,

4. financial distress minimisation, ie, the avoidance of unanticipated significant financial obligations for lot owners,

5. minimisation of disharmony between the $\mathrm{MOH}$ lot owners who collectively own the common property. 
It should be noted that these criteria are not necessarily compatible. This signifies that a common property capital expenditure funding method will likely involve some compromise with respect to achieving objectives relating to all of the criteria.

\subsection{Alternative approaches to funding MOH common property capital expenditure}

Three approaches to funding $\mathrm{MOH}$ common property capital expenditure can be identified. This section describes the three approaches.

\subsection{Funds raised from owners at the time common property capital expenditure is required}

This method involves the raising of an atypically large one-off contribution from lot owners around the time the common property capital expenditure is to be made. The raising of a large one-off contribution is widely referred to as a 'special levy' in Australia and a 'special assessment' in the USA. The term 'special levy' will be used here.

\subsection{Debt funding}

Debt funding (sometimes referred to as 'debt financing', 'loan financing' or 'borrowing') refers to the taking up of a loan provided by an independent financier or the taking of extended credit period terms to reimburse a service provider for common property repairs and replacement work undertaken. The factor that these approaches have in common is that they require lot owners to provide contributions over a protracted time period pursuant to the conduct of common property repairs and replacement. The primary focus in this paper will be on a loan provided by an independent financier.

A problem for the debt funding model is that common property does not lend itself to use as loan collateral. This is because it is rare for common property to be physically separable from the privately owned units in a $\mathrm{MOH}$ scheme. An alternative is for unit owners to pledge their own dwelling as collateral for the loan, however, as Lujanen (2010: 182) notes: "It is understandable that not all owners are willing to pledge their dwellings for loans as collateral for certain types of major repair activity”. As a consequence, a loan to finance common property capital expenditure can be expected to carry interest charges commensurate with unsecured loans.

\subsection{Owner contribution to an accumulating fund prior to common property capital expenditure}

In Australia an accumulating fund that is contributed to by owners for the purpose of funding future common property capital expenditure is generally termed a 'sinking fund', in the USA it is termed a 'reserve fund'. The term 'sinking fund' will be used here.

A variety of policy approaches to sinking funds are evident across jurisdictions. Many $\mathrm{MOH}$ schemes in the USA levy a mandatory contribution that is based on a set percentage of the cost of administering the scheme. This approach has the advantage of being simple to calculate and administer. On the negative side, however, it is a somewhat arbitrary approach as the amount of a scheme's administrative expenditure has a limited relationship with its common property capital expenditure requirements. In Australia, the general approach is to link sinking fund contributions to forecast common property capital expenditures. When we recognise the degree of subjectivity that is involved in forecasting common property capital expenditures, and the scope for unforeseen expenses such as the correction of unanticipated common property damage, it becomes evident 
that operation of a sinking fund does not avert the possibility of needing to raise supplementary capital, perhaps by way of a special levy or loan.

\subsection{Appraising the relative merits of the three funding options}

The appraisal of the relative merits of the three funding options has been structured according to the criteria outlined above. The five subsidiary criteria will be considered first.

\subsection{Owner cost minimisation over the life of a complex}

The one-off nature of a special levy signifies that its administrative collection costs are likely to be low relative to the recurrent costs associated with collecting sinking fund levies or collecting loan servicing levies. Although this suggests that the special levy can be relatively simple to administer and cost effective, this would only appear to be the case for those $\mathrm{MOH}$ complexes where it operates smoothly. Raising a special levy does not signify that all owners will have a willingness or capacity to pay the levy. There can be substantial delays and emotional frustration involved in trying to enforce the payment of large outstanding special levies. In extreme cases, the $\mathrm{MOH}$ scheme may have to force the sale of a defaulting lot. Delays in obtaining the funds from all lot owners can result in the incurrence of administrative costs associated with chasing payments and also accelerated physical deterioration costs arising from failure to conduct required maintenance in a timely manner. While raising a special levy avoids the costs associated with involving a lending institution that are apparent if a loan is raised, this saving will not accrue to those owners who need to raise a personal loan to fund the special levy. For those special levy situations that result in many owners raising a personal loan, the transaction costs associated with raising one loan at the whole of complex level can be expected to be less than the total of the transaction costs associated with the raising of many lot owner personal loans.

The sinking fund also does not appear to be a strong performer with respect to the cost minimisation criterion. In many $\mathrm{MOH}$ legal jurisdictions, sinking funds are required to be held in trust accounts, signifying low risk and concomitant low yield returns over the long term. More risky investments, such as a share portfolio, typically earn higher returns over the long term. This signifies that if a $\mathrm{MOH}$ complex has fairly affluent owners, these owners will be experiencing an opportunity cost by paying funds into a sinking fund that over the long-term is likely to provide a lower return than they could have earned had the funds been left in owners' diversified share portfolios. In the case of less affluent owners who may be carrying credit card debt, the source of the opportunity cost of sinking fund levies is the cost of the incremental credit card debt raised. This cost will be much greater than the fixed rate of return that the funds would earn if held in a $\mathrm{MOH}$ sinking fund account. Both these scenarios signify that, from a cost minimisation perspective, rather than raising a sinking fund, it would be better to defer the collection of funds for common property capital expenditure. Where a sinking fund is based on periodically conducted capital expenditure forecasts, the commissioning fee associated with preparing the forecasts represents a further cost associated with the sinking fund approach.

In light of the substantial costs that can arise if administering a large special levy and the opportunity, set up and administration costs associated with operating a sinking fund (in most situations the opportunity costs will likely be significantly greater than set up and administration costs), it appears that the loan option is the strongest performer with respect to the cost minimisation criterion. Complications arise, however, when attempting to compare the cost of the loan funding model with the cost of the special levy. This is because different lot owners would 
incur different costs to fund the special levy payments. Some owners might increase their property mortgage to fund the levy, while others may incur the cost of increased credit card debt, while others would lose returns earned on diminished investments. Experience suggests that mortgage loan interest rates are lower than $\mathrm{MOH}$ common property loan interest rates, but that $\mathrm{MOH}$ common property loan interest rates are much lower than credit card interest rates. Once the relative interest rate costs have been determined, they would then need to be translated into after tax amounts, ie we would need to consider whether the investor owner lives in a jurisdiction where the cost of servicing a loan raised to cover special levy charges is tax deductible, and also whether an owner's share of the payments to service the costs of a loan taken up by a MOH scheme are tax deductible. These factors can be expected to vary across taxation jurisdictions.

\subsection{Horizontal equity}

As noted earlier 'horizontal equity' refers to the equitable allocation of cost across individual lot owners at a particular time juncture. It has just been noted that a special levy heightens the chances of lot owners being overdue in the payment of their levies, or even in some cases defaulting on the levy and the volunteer owners executive committee may choose not to pursue the outstanding levy due to the emotional issues or administrative challenge that can surround such an action. Such a scenario is clearly inconsistent with the promotion of horizontal equity and signifies that the raising of large special levies as a financing option ranks low on this criterion. The issue of overdue levies raises the question of whether interest should be levied on an overdue account together with a charge for administrative costs incurred in managing the outstanding account. If no interest and/or no administrative fee is levied, horizontal inequity would be apparent.

It has already been noted that most loans extended to $\mathrm{MOH}$ schemes are unsecured. This signifies that in the event of a lot owner being slow in paying a levy that has been triggered by a loan repayment schedule, the liability for repayment will fall on the remaining lot owners in the scheme. In a small $\mathrm{MOH}$ scheme comprising four owners where two owners are facing personal bankruptcy, there could be a protracted period in securing the loan repayment related levies from all lots. This could place the remaining owners in a position of having to temporarily meet the debt repayment shortfall. Such horizontal inequity is unlikely to be as acutely felt if a sinking fund is operated, as there is no independent party seeking repayment of capital in accordance with a contractual loan repayment schedule. It should be noted, however, that a loan repayment schedule smooths over time the lot owner's allocation of common property funding repayments, resulting in a lower risk of overdue payments when compared to special levy funding. This extended time frame provides greater opportunity to pursue courses of action designed to collect overdue levies.

So long as $\mathrm{MOH}$ lot entitlement and obligations have been established on an equitable basis, the sinking fund option does not appear to promote any horizontal inequities. While it has just been noted that overdue levies are more likely to arise in the context of special levy funding relative to debt funding, their incidence is expected to be lower still for the sinking fund arrangement, as first purchasers in a new complex, as well as all subsequent purchasers, will be immediately aware of the need to fund common property capital works.

\subsection{Temporal equity}

As noted above, 'temporal equity' refers to the equitable allocation of costs to different lot owners over the life of a MOH complex. This principle holds that regardless of whether the time period of lot ownership coincides with common property expenditure, the lot owner should make a 
contribution to paying for common property maintenance that equates to the lot's pro-rated share of common property deterioration during the owner's period of ownership. This notion can be linked to the accrual principle in accounting that seeks to allocate expenses to those time periods associated with resource consumption or depletion.

The special levy funding method is fundamentally inconsistent with the temporal equity principle. Imagine the exterior wall of a MOH complex is painted every six years. An individual may purchase a lot in the complex six months after the exterior wall was painted and the special levy notice served to lot owners, then sell the lot 5 years later, just prior to a second painting special levy notice is served on lot owners. This would signify that although the individual owned a lot for the vast majority of the time associated with the painting life cycle, they made no contribution towards the cost of painting.

It should be noted, however, that if common property work has the potential to have a positive impact on the value of a lot (signifying that the common property benefit resulting from the work is readily discernible), the horizontal inequity associated with special levy funding would be greatly mitigated. This is because the lot owner who would stand to gain from the enhanced property value deriving from the common property work undertaken would be the party paying for the lot's share of the common property's enhancement cost.

The debt financing option also does not appear to perform well with respect to the temporal equity criterion. Similar to the scenario just outlined, if a lot owner sells their lot six years into the life of a MOH complex, they will pay nothing towards the costs associated with rectifying complex deterioration if all rectification work was to commence seven years into the complex's life and be funded by a loan. This temporal inequity stemming from loan financing becomes less pronounced as a complex ages, however. This is because major cyclical common property repair work undertaken will result in continuous loan repayments being made by lot owners, ie the loan repayment mechanism works to spread the cost of common property rectification work overtime. This signifies that regardless of whether an owner owned a lot in a complex between the $11^{\text {th }}$ and $15^{\text {th }}$ years of its life, which may happen to coincide with some major common property repair works, or owned a lot in the same complex between the $13^{\text {th }}$ and $17^{\text {th }}$ years of its life, which may happen to not coincide with some major common property repair works, both would likely pay a similar amount towards common property funding due to the smoothing effect of loan servicing costs. This rationale maintains if common property expenditure is cyclical, however, it breaks down where common property expenditures are less cyclical and characterised more by sporadic large one-off payments. While a due diligence appraisal can inform a lot purchaser of debt encumbrances of a $\mathrm{MOH}$ scheme (thereby mitigating temporal equity concerns, as the purchaser can factor the debt encumbrance into their offer price determination), it is unlikely to uncover the fact that a major one-off roof overhaul is shortly required for the building and that a loan will have to be raised.

It is notable that as sinking funds involve the raising of funds progressively across the lifecycle of common property maintenance and replacement expenditures, of the three funding options under examination, the sinking fund appears to perform best with respect to achieving temporal equity. The extent to which the sinking fund option is stronger with respect to the temporal equity criterion would be less marked in complexes where potential lot purchasers can readily discern the physical standing of common property and the extent to which it needs a major overhaul or replacement. If the condition of common property is readily discernible to a purchaser, then the quality of common property upkeep can be expected to influence the value attributed to a lot. This would signify that 
the saving an owner might make by not contributing towards common property deterioration that coincides with their period of lot ownership, would be offset by a negative impact on their lot's value, as a result of common property deterioration.

\subsection{Financial distress minimisation}

As noted above, 'financial distress minimisation' refers to the avoidance of unanticipated significant financial obligations for lot owners. Special levies are not conducive to conditioning lot owners to anticipate the amount and timing of their property ownership expenses. While many people do not develop personal expenditure budgets, few of the lot owners who do can be expected to have sufficient knowledge of the status of common property assets, nor the costs involved in their long-term maintenance, to develop a well-informed personal budget. This signifies a compromised capacity for a prospective lot purchaser to determine whether they will be able to afford the on-going costs associated with their intended purchase. During periods of high complex repair and replacement cost inflation, some lot owners will experience significant financial distress due to their incapacity to fund their share of common property capital expenditure as a lump sum.

As a consequence of the way in which a loan repayment schedule spreads the burden of lot owners' funding of common property capital expenditure over time, the financial distress issue appears to be lessened for the debt funding option. Nevertheless, the loan approach can still be expected to trigger unanticipated financial obligations for lot owners when loan repayment levies are first raised in a complex, particularly if an unusually large loan has to be raised to fund a significant one-off common property related expenditure.

For owners of lots in a $\mathrm{MOH}$ complex that has a sinking fund raised on the basis of sound capital works projections, a significant aspect of uncertainty associated with their investment will have been removed. This diminished uncertainty signifies a lower propensity for lot owner financial distress.

\subsection{Lot owner disharmony minimisation}

It has already been noted that some lot owners might experience problems covering the cost of special levies raised. This underscores the fact that the special levy funding approach can adversely affect community harmony. The significance of this issue can be expected to increase as a complex ages and resistance to paying special levies results in an augmentation of common property neglect. Guilding et al (2005) comment on a downward spiralling effect that can be invoked once the physical standing of a MOH complex's common property assets begins to fall and there are insufficient funds to pay for needed rectification work.

In terms of the volatility of levies over time, for reasons already outlined above, the special levy approach will result in the most volatile levies, the loan funding approach will result in moderate levy volatility (once a MOH scheme commences a recurring cycle of capital expenditures), and the sinking fund approach will lead to lowest levy volatility. This suggests the potential for community disharmony is greatest in the context of special levies and lowest in the context of sinking funds.

A subtle, but important, role played by the raising of sinking funds concerns the manner in which repeated financial levies paid by lot owners would instil an expectation with respect to the need for common property capital outlays. Alternately stated, the payment of capital works levies in advance of capital works, conditions lot owners to expect capital works expenditure. This signifies 
the development of a shared vision and expectation with respect to common property capital expenditures. So long as a sinking fund is aligned to an appropriately developed common property capital expenditure budget, the payment of sinking fund contribution levies can be viewed as representing a tacit approval of the expenditures foreshadowed in the budget. The maintenance of a sinking fund that is based on a forecasted need for expenditure can thus be seen to constitute an important unifying vehicle for the owners in a $\mathrm{MOH}$ scheme. This greater unification can be seen as consistent with lessening a potential for disharmony.

\subsection{Common property sustainability}

All of the issues discussed above can be seen to feed into the "common property sustainability" criterion, however there are some broad issues that do not lend themselves to integration with any element of the five subsidiary criteria framework already discussed in this section. These broad issues will now be addressed.

Decisions about if, and when, common property maintenance work is to be undertaken in a complex that is reliant on special levy funding can be detrimentally influenced by each individual lot owner's perception of their personal financial position at the time the vote to undertake the capital work is taken. This signifies that the sustainability of common property in its original condition will be undermined by a potential for common property maintenance expenditure authorisation being influenced more by the financial standing of the particular mix of a $\mathrm{MOH}$ complex's owners at the time the authorisation is being sought, rather than the physical standing of a complex and the urgency of needed building rectification work. It follows that the long term interests of an owner of a lot in MOH complex A can be compromised because the complex happens to have a mix of financially challenged owners, while the long term interests of a lot owner in the equivalent neighbouring complex B are not compromised because complex B happens to have a mix of wealthy owners. The significance of this relative wealth issue to the likelihood of capital works authorisation is mitigated should the sinking fund alternative be adopted.

A particular problem associated with the loan approach to funding relates to the owners' capacity to comprehend the loan implications. The documentation associated with loans is rarely written in a manner that is readily comprehensible to lot owners who are seeking to make an informed decision about the nature of liabilities and costs associated with entering into a loan arrangement. Once a motion to raise a loan has been passed, there is no guarantee that on the date the common property rectification work is required, the requisite funds can be raised from an acceptable source and on reasonable terms. This issue is particularly pertinent given the relatively recent world-wide banking liquidity crisis. While this problem is also apparent, to an extent, for special levies (many lot owners may need to raise personal loans to finance their payment of a special levy), it is not apparent for the sinking fund approach. A risk also arises with respect to whether, at the time common property capital work is required, the financial position of the $\mathrm{MOH}$ scheme will satisfy the lending institution's lending criteria. A MOH scheme that repeatedly relies on loan funding to pay for common property expenditure funding could be accorded a low credit rating. This could result in more expensive loan financing and might compromise the scheme's recourse to emergency funding, should large and unforeseeable expenses relating to a problem such as a structural defect arise.

A key feature of the sinking fund approach to common property capital expenditure funding is that it breaks the contemporaneous link between the timing of a vote on an expenditure proposal and the incurrence of a levy liability relating to the expenditure. It is likely to be easier for lot owners to 
approve proposed common property expenditure that is well-supported on engineering grounds, if the decision to proceed with the expenditure is isolated from the financing question. The financing question does not have to be considered if the requisite funds have already been accumulated in a sinking fund.

If major unplanned expenditure due to structural defects is required, particularly in an older $\mathrm{MOH}$ complex where cyclical capital maintenance expenditures are at their highest, lot owners would appear to have greatest flexibility in connection with when and how they fund the work if a sinking fund has been accumulated. This is because even if the sinking fund balance is not the final source of finance, in many jurisdictions it can be temporarily drawn upon and treated as a bridging finance source of funds.

Table 1 provides a summary of the outcomes of the foregoing discussion. It should be noted, however, that the degree of relative merit recorded in Table 1's cells has been made at a somewhat broad and generic level of abstraction. This is because the relative merit of the three funding options under examination can be affected by characteristics of a particular $\mathrm{MOH}$ scheme. For instance, in an old scheme that has no sinking fund and is in need of some immediate remedial building work to arrest accelerating dilapidation, the raising of a loan may be the most viable approach for satisfying the holistic "common property sustainability" criterion. This is because work can be carried out immediately and without a need to wait for a requisite sinking fund balance to accumulate and without having to wait through a protracted period of trying to get unit owners to support the raising of a substantial special levy.

\section{INSERT TABLE 1 ABOUT HERE}

\subsection{Conclusion and Discussion}

This paper has investigated the relative merits of three $\mathrm{MOH}$ common property capital expenditure funding models: the special levy, the loan, and the sinking fund. From the analysis provided, it appears that at a generic level of abstraction, the sinking fund approach is preferable as the primary source of funding. It should be acknowledged, however, that a degree of subjectivity is bound to be exercised in making such a call. A major reason for this is that owners' executive committees across MOH schemes and also owners, both across and within schemes, will attach differential weightings to the assessment criteria outlined herein. For example, in complexes where owners and executive committees see cost minimisation as of paramount importance, if a loan can be raised at a competitive interest rate, debt funding may be the preferred financing approach.

Key contingency factors relating to a $\mathrm{MOH}$ complex and its owners will affect the relative desirability of the three funding models. For example, it has been noted that a sinking fund approach can serve to unify lot owners by conditioning them to expect certain common property expenditures. This need to unify owner expectations is likely to be much greater in a large 500 lot $\mathrm{MOH}$ complex than in a 6 lot complex where the owners might engage in more extensive communications with one another.

The breadth of permutations relating to a MOH complex’s characteristics such as age, size, location, extent and nature of common property, together with variations in owner demographics and financial profiles across schemes combine to generate a vast array of $\mathrm{MOH}$ scheme specifics. 
These factors highlight the challenge for government policy makers seeking to legislate for common property funding using a "one size fits all" philosophy. The need to recognise scheme specific factors in drafting legislation concerning a requisite common property funding approach has been recognised in several jurisdictions. ${ }^{\text {iii }}$

While the special levy approach has rated poorly across all the criteria considered in this paper, where the per lot capital expenditure on common property is small over the life of a $\mathrm{MOH}$ complex, the special levy alternative may work well. This is so long as the special levies do not reach levels that would create lot owner financial distress. If a $\mathrm{MOH}$ scheme has limited common property relative to the number of lot owners, and if the scheme is of a nature that it attracts relatively affluent owners, the special levy would appear to have the capacity to satisfy the principle criterion of maintaining common property at a level consistent with its standing at the beginning of the MOH complex's life. While this approach would still suffer from deficient temporal equity, the extent of temporal inequity created would be mitigated if the per lot special levies are small.

Generally, debt funding would appear to represent a stronger basis of funding than special levies. Relative to special levies, debt funding carries the advantage of smoothing the funding of common property capital expenditure over an extended time period. Once a complex's cycle of common property expenditure has commenced, from a lot owner's cash flow perspective, the debt funding model starts to resemble the sinking fund model, ie, under both models a lot owner is making regular payments to fund common property capital expenditure. This signifies greater intertemporal equity and financial distress minimisation for the loan model relative to the special levy model. The loan model would appear to be a particularly viable alternative when seeking to fund large unanticipated works that have not been included in a common property capital expenditure budget, thereby resulting in a sinking fund shortfall.

An important factor bearing on the relative merit of the funding options under consideration is the transparency of information available to purchasers of lots and also the capacity of potential purchasers to appropriately factor information relating to common property capital expenditure funding into the amount they are willing to pay for a lot. The temporal equity concern relating to debt funding lessens if purchasers have the capacity to determine the amount of debt associated with a lot they are purchasing and also the physical status of common property, and then adjust the price they are willing to pay accordingly. Similarly, the sinking fund mechanism can be expected to be supportive of community harmony if current lot owners know that the accumulated value of the sinking fund will be appropriately factored into the price a prospective lot purchaser is willing to pay for their lot. ${ }^{\text {iv }}$ Due to the growth of the $\mathrm{MOH}$ sector, a growing proportion of the population are gaining $\mathrm{MOH}$ property ownership experience. This will likely result in greater $\mathrm{MOH}$ lot purchaser sophistication and an increasing proportion of purchasers attaching greater importance to the size of a complex's accumulated sinking fund and also the size of any debt outstanding.

It would be misleading to suggest that the criteria outlined here represent a definitive listing of factors that should be considered when determining what common property capital funding approach should be taken. Some may feel that the "disharmony minimisation" criterion is too under-defined as a construct and may prefer to replace it with a related criterion such as "promotion of community spirit”. Also, other new criteria might be seen as warranting recognition, for instance one could consider "speed of fund access", to deal with an emergency expenditure situation, as an additional criterion. 
It should be recognised that this paper has been written in the context of a relative conceptual vacuum, ie, it has been prepared without the benefit of any prior literary examination of the MOH common property capital funding issue. This signifies that the work should be viewed in an exploratory light. This is particularly the case given the a priori rationale that provides the platform for the concepts advanced. This approach signifies the study is vulnerable to the possible exercise of subjectivity. This weakness may have been mitigated somewhat, however, by the fact that one of the authors practices in the field and has accumulated many years of experience advising owner committees on common property capital expenditure matters including the budgeting and funding of common property capital expenditure.

The implications of the analysis provided in this paper appear to be profound. For government policy makers wrestling with whether unit owner contributions to sinking funds should be mandated (eg, see New South Wales State Government discussion paper (2012)), this paper constitutes the first attempt to provide a considered rationale with respect to the merits of alternative common property funding options. For property managers who need to advise owner committees on whether a sinking fund should be raised for their building, this paper is the first to provide a framework that can be drawn upon to explain the relative merits of alternative common property capital expenditure funding options. The insights provided by the paper can greatly assist owner committees when asked by unit owners to justify the raising of levies well in advance of future common property capital expenditures. In combination, these factors signify that the implications of the study for practice and society are considerable.

With respect to implications for the research community, the originality of the study signifies it has flagged an uncharted research arena. No empirical research has been directed to examining the relative merits of the three common property funding options. Different lines of research that could build on the study include:

1) Survey or interview unit owners to appraise satisfaction levels across buildings that use different approaches to funding common property capital expenditure.

2) Survey or interview property managers to appraise the merits of alternative approaches to funding common property capital expenditure.

3) Conduct a series of case study investigations designed to appraise the workings and relative performance of the three funding options under examination.

Further research work could also attempt to develop a ranking of the relative importance of the funding appraisal criteria advanced herein. Such an attempt could be pursued by way of empirical data collection, with attitudes towards the relative importance of the criteria secured from $\mathrm{MOH}$ managing agents and lot owners with owner executive committee experience. It would also be useful to provide an examination of the key property and owner related contingency factors that impact on the relative merit of the three funding options described herein. Likely factors include, $\mathrm{MOH}$ scheme size (in terms of number of lots), the per lot value of common property owned and managed by a scheme, the technological complexity of the common property owned, the ease with which the physical standing of common property can be appraised by lot owners, and the relative wealth of lot owners. 


\section{References}

Blandy, S., Dixon, J. and Dupuis, A. (2006), "Theorising power relationships in multi-owned residential development: unpacking the bundle of rights”, Urban Studies, 43(13), 2365-2383.

Blandy, S., Dixon, J. and Dupuis, A. (2010), Multi-owned Housing: Law, Power and Practice, Ashgate: Farnham, England.

Cassidy K and Guilding, C. (2011), "Management models and differential agency challenges arising in Australian multi-titled tourism accommodation properties”, Tourism Management, 32, 1271-1281.

Christudason, A. (2004), "Common property in strata titled developments in Singapore: common misconceptions”, Property Management, 22(1), 14-28.

Easthope, H., Randolph, B. (2009), “Governing the Compact City: The Challenges of apartment living in Sydney, Australia”, Housing Studies, 24, 243-259.

Easthope, H. Randolph, B. and Judd, S. (2012), Governing the Compact City: The Role and Effectiveness of Strata Management, City Futures, Faculty of the Built Environment, University of New South Wales.

Encon, Y.Y.H., (2005), "Key success factors of building management in large and dense residential estates”, Facilities, 23(1/2), 47-62.

Everton-Moore, K., A. Ardill, C. Guilding and Warnken, J. (2006), “The law of strata title in Australia: A jurisdictional stocktake.” Australian Property Law Journal, 13(1): 1-35.

Gruis, V., Nieboer, N. and Tsenkova, S. (eds) (2009), Management of Privatised Social Housing: International Perspectives, Wiley-Blackwell, Oxford.

Guilding, C., Warnken, J., Ardill, A. and Fredline, L. (2005), “An agency theory perspective on the owner/manager relationship in tourism-based condominiums.” Tourism Management, 26(3): 409420.

Guilding, C. and Whiteoak, J (2008), “An examination of management and governance issues arising in residential golf complexes”, Pacific Rim Property Research Journal, 14(1), 44-65.

Lujanen, M. (2010), "Legal Challenges in ensuring regular maintenance and repairs of owneroccupied apartment blocks”, International Journal of Law in the Built Environment, Vol 2(2), 2010.

Muhamad Ariff, N.R. and Davies, H. (2011), Multi-owner low-cost housing management in Malaysia: Effects of owner-occupant characteristics and occupancy rates, International Journal of Housing Markets and Analysis, 4(3), 268-289.

New South Wales Fair Trading, (2012), Strata \& Community Title Law Reform Discussion Paper, New South Wales Government Fair Trading Office. 
Ngai-ming, Y. and Forrest, R. (2002), "Property owning democracies? Home owner corporations in Hong Kong”, Housing Studies, 17(5), 703-720.

Randolph, B., (2006), Delivering the compact city in Australia: current trends and future implications”, Urban Policy and Research, 24(4), 473-490.

Schuetze, W. (1993), “What is an asset?” Accounting Horizons, 7(3): 66-70.

Sherry, C. (2006), “Termination of strata schemes in New South Wales - proposals for reform” Australian Property Law Journal, 13, 227 - 239.

Walters, M., (2002), “Transaction costs of collective action in Hong Kong high rise real estate”, International Journal of Social Economics, 29(2), 299-314.

Warnken J and Guilding, C. (2009), “Multi-ownership of tourism accommodation complexes: a critique of types, relative merits, and challenges arising”, Tourism Management, 30, 5, 704-714. 


\footnotetext{
i [For elaboration on what constitutes 'capital expenditure', see Schuetze (1993).]

ii [Condominium complexes are more generally referred to as 'strata title' complexes in Australia.]

iii [For example, the Australian state of Victoria requires a sinking fund to be established only in those MOH schemes that have more than 100 units or an annual operating budget exceeding $\$ 200,000$.]

iv [Anecdotal commentaries provided by managers experienced in the MOH property sector suggest purchasers of lots do not tend to adequately factor in the accumulated value of sinking funds when determining a lot's purchase value.]
} 
TABLE 1

Summary of relative merit of three sources of MOH common property capital funding

\begin{tabular}{|l|c|c|c|}
\hline Cost efficiency & Special levy & Debt finance & Sinking fund \\
\hline Horizontal equity & Depends on ease & Fairly high & Low \\
\hline Temporal equity & Low & $\begin{array}{c}\text { Generally high, } \\
\text { compromised if a } \\
\text { default arises }\end{array}$ & High \\
\hline $\begin{array}{l}\text { Financial distress } \\
\text { minimisation }\end{array}$ & Low & Fairly low & High \\
\hline $\begin{array}{l}\text { Promotion of } \\
\text { community } \\
\text { harmony }\end{array}$ & Low & Low/moderate & High \\
\hline $\begin{array}{l}\text { Common property } \\
\text { sustainability }\end{array}$ & Low & Moderate & High \\
\hline
\end{tabular}

